\title{
Inactivation of milk-borne pathogens by blue light exposure
}

\author{
C. dos Anjos, ${ }^{1}$ F. P. Sellera, ${ }^{1}$ L. M. de Freitas, ${ }^{2}$ R. G. Gargano,,${ }^{1}$ E. O. Telles, ${ }^{3}$ R. O. Freitas, ${ }^{4}$ M. S. Baptista, ${ }^{2}$ \\ M. S. Ribeiro, ${ }^{5}$ N. Lincopan, ${ }^{6,7}$ F. C. Pogliani, ${ }^{1}$ and C. P. Sabino ${ }^{6,8 *}$ \\ ${ }^{1}$ Department of Internal Medicine, School of Veterinary Medicine and Animal Science, University of Sao Paulo, Sao Paulo, SP, Brazil, 05508-270 \\ ${ }^{2}$ Department of Biochemistry, Institute of Chemistry, University of Sao Paulo, Sao Paulo, SP, Brazil, 05513-970 \\ ${ }^{3}$ Department of Preventive Veterinary Medicine and Animal Health, School of Veterinary Medicine and Animal Science, University of Sao Paulo, \\ Sao Paulo, SP, Brazil, 05508-270 \\ ${ }^{4}$ Brazilian Synchrotron Light Laboratory, Brazilian Center for Research in Energy and Materials, 13083-970, Campinas, SP, Brazil, $13083-970$ \\ ${ }^{5}$ Center for Lasers and Applications, Nuclear and Energy Research Institute, Sao Paulo, SP, Brazil, 05508-000 \\ ${ }^{6}$ Department of Clinical and Toxicological Analysis, School of Pharmaceutical Sciences, University of Sao Paulo, Sao Paulo, SP, Brazil, 05508-000 \\ ${ }^{7}$ Department of Microbiology, Institute for Biomedical Sciences, University of Sao Paulo, São Paulo, SP, Brazil, 05508-000 \\ ${ }^{8}$ BioLambda, Scientific and Commercial Ltd., Sao Paulo, SP, Brazil, 05360-030
}

\section{ABSTRACT}

Food safety and quality management play a pivotal role in the dairy industry. Milk is a highly nutritious food that also provides an excellent medium for growth of pathogenic microorganisms. Thus, dairy industry focuses most of their processes and costs on keeping contamination levels as low as possible. Thermal processes for microbial decontamination may be effective; however, they cannot provide excellent organoleptic, nutritional, and decontamination properties simultaneously. In this scenario, microbial inactivation by exposure to blue light is a promising alternative method in the food industry due to its intrinsic antimicrobial properties free of any thermal effect. Therefore, this study aimed to determine the inactivation kinetics induced by blue light $(\lambda=413 \mathrm{~nm})$ against Staphylococcus aureus, Escherichia coli, Pseudomonas aeruginosa, Salmonella Typhimurium, and Mycobacterium fortuitum cells suspended in whole milk or saline solution. We also performed a series of optic spectroscopies to investigate possible degradation of milk components. All species were sensitive to photoinactivation suspended either in saline solution or milk. Inactivation kinetics differs significantly depending on the suspension medium and each species is differently affected. All bacterial species tested presented more than $5 \log _{10}$ of inactivation within less than $2 \mathrm{~h}$ of irradiation $\left(720 \mathrm{~J} / \mathrm{cm}^{2}\right)$. Infrared spectroscopy did not reveal any significant alteration in any of the milk constituents (e.g., sugars, proteins, and lipids). Riboflavin (vitamin $\mathrm{B}_{2}$ ) was the only sig-

Received April 5, 2019.

Accepted August 5, 2019.

*Corresponding author: caetanosabino@gmail.com nificantly degraded constituent found. Therefore, we conclude that microbial inactivation performed by blue light presents extraordinary potential for processes in the dairy industry.

Key words: food pathogen, food borne, milk decontamination, photoinactivation, visible light

\section{INTRODUCTION}

Milk is one of the most widely consumed foods worldwide. Due to its highly nutritious nature, milk is an extremely fertile medium for growth of pathogenic microorganisms, which can cause direct or indirect illness (i.e., the bacteria itself or toxins; Johler et al., 2015; Sonnier et al., 2018). Currently, the widespread use of antibiotics in livestock animals also brings a perfect environment for the emergence of drug-resistant pathogens that can trigger infection outbreaks among animals and humans (WHO, 2014; Sartori et al., 2017). Therefore, microbial contamination in dairy products plays an important role in the spreading of clinically important pathogens to humans (Diab et al., 2017).

Microbial control is the main pillar of food safety standards in the food industry. The rigorous requirements over logistics and food safety management sectors of dairy industries demand effective control strategies against any source of microbial contamination (Boor et al., 2017). Thermal decontamination methods, such as pasteurization and UHT processing, are the only antimicrobial strategies legally accepted nowadays; however, they are incapable of providing excellent organoleptic, nutritional, and decontamination properties simultaneously (Scheldeman et al., 2006).

Currently, the idea of replacing thermal processes for alternative decontamination technologies is gaining scientific and technological relevance. Previous studies have demonstrated the inactivation of microorganisms 
in milk by pulsed light (Miller et al., 2012), continuous UV light (Matak et al., 2007), and high-intensity pulsed light (Palgan et al., 2011). Photoinactivation of bacteria by blue light has also attracted the attention of other sectors of food industry (Ghate et al., 2013, 2015, 2016; Srimagal et al., 2016). Srimagal et al. (2016) evaluated the antimicrobial activity of blue light for the first time in milk samples experimentally contaminated with E. coli. In that study, they also demonstrated an increase in the shelf life of blue-light-treated samples in relation to pasteurized controls (Srimagal et al., 2016). Therefore, this approach presents potential advantages in contrast to conventional methods: it is cost effective, safer in production line, and to final consumers, preserves more nutrients, and may significantly increase the product's shelf life.

Antimicrobial activity of blue light is associated with the presence of photosensitive endogenous compounds broadly found in pathogens, such as porphyrins and flavins. These molecules can absorb light at specific wavelengths and, hence, are promoted to excited energy states (Dai et al., 2013). Excited molecules in the triplet state can promote photodynamic reactions and locally generate reactive oxygen species (ROS). The generated ROS then react with multiple cellular components further causing microbial cell death by oxidative damage (Huang et al., 2012). Even though it is governed by photodynamic reactions, microbial inactivation by blue light it is not often referred to as photodynamic therapy because there is no addition of an exogenous photosensitizer, being therefore classified as photoinactivation or blue light inactivation.

In the present study, we investigated the photoinactivation kinetics of bacterial species that are recognized as important contaminants of milk and its derivatives in pre- and postprocessing stages (Johler et al., 2015; Sonnier et al., 2018). The biomolecular composition of irradiated milk was also analyzed by a series of nondestructive light spectroscopy techniques to track relevant chemical alterations from the light-mediated inactivation method.

\section{MATERIALS AND METHODS}

\section{Bacterial Strains}

For this study, we selected a total of 5 bacterial strains: 4 from the American-type culture collection (ATCC; Manassas, VA; Staphylococcus aureus ATCC 25923, Escherichia coli ATCC 25922, Pseudomonas aeruginosa ATCC 27853, and Salmonella Typhimurium ATCC 14028, and 1 from the National Collection of Type Cultures Mycobacterium fortuitum NCTC 8573).

\section{Light Source}

A blue light-emitting diode (LED) device $(\lambda=413$ $\pm 10 \mathrm{~nm}$, LEDsaber, BioLambda, São Paulo, SP, Brazil) was used at an irradiance level of $100 \mathrm{~mW} / \mathrm{cm}^{2}$. The LED probe was placed on a holder $1 \mathrm{~mm}$ above the surface of a 24 -well plate where samples were placed.

\section{Experimental Milk Contamination}

Before experiments, fresh individual colonies were collected from brain heart infusion agar (Difco, Detroit, $\mathrm{MI}$ ), inoculated into $3 \mathrm{~mL}$ of Mueller-Hinton broth (Difco), and incubated at $37^{\circ} \mathrm{C}$ for $24 \mathrm{~h}$ under a shaking regimen $(100 \mathrm{rpm})$. The cultures were then individually washed twice with PBS or PBS $+0.05 \%$ Tween 80 (only for M. fortuitum). For each washing step, the cells were collected by centrifugation at 7,378 $\times g$ for $10 \mathrm{~min}$ at room temperature. After the second washing step, cells were suspended in PBS for the preparation of the working inocula.

The concentration of each inoculum was determined by assessing the turbidity of the suspension with a spectrophotometer. The absorbance of the bacterial suspensions at $625 \mathrm{~nm}$ was adjusted to 0.09 , which corresponds to a concentration of approximately $10^{8} \mathrm{cfu} /$ $\mathrm{mL}$. For the photoinactivation assays, the PBS bacterial suspensions were diluted in either UHT bovine milk or PBS to a working concentration of $10^{7} \mathrm{cfu} / \mathrm{mL}$. One milliliter of each sample was individually placed in 12well plates for the blue light irradiation procedure.

\section{Experimental Design}

The experimental groups were compared with their respective control groups, which did not receive any light. Pilot experiments were performed with each bacterial species collecting samples in time intervals of 30 min before defining the optima light exposure times for each. With the preliminary results, we defined the following irradiation time and energy density shown in Table 1.

After treatments, samples were serially (1:10) diluted in PBS and seeded onto Mueller-Hilton agar plates, according to the technique described by Jett et al. (1997) for $\mathrm{cfu} / \mathrm{mL}$ determination. Plates were incubated at $37^{\circ} \mathrm{C}$ for $24 \mathrm{~h}$ (S. aureus, E. coli, P. aeruginosa, and Salmonella Typhimurium) or $48 \mathrm{~h}$ ( $M$. fortuitum) for colony counting. Survival fraction values were calculated according to Equation [1]:

$$
\text { survival fraction }=\log _{10}\left(\frac{N_{0}}{N}\right) \text {, }
$$


Table 1. Medium, time ( $\mathrm{min})$, and radiant exposure $\left(\mathrm{J} / \mathrm{cm}^{2}\right)$ used for each bacterial species evaluated

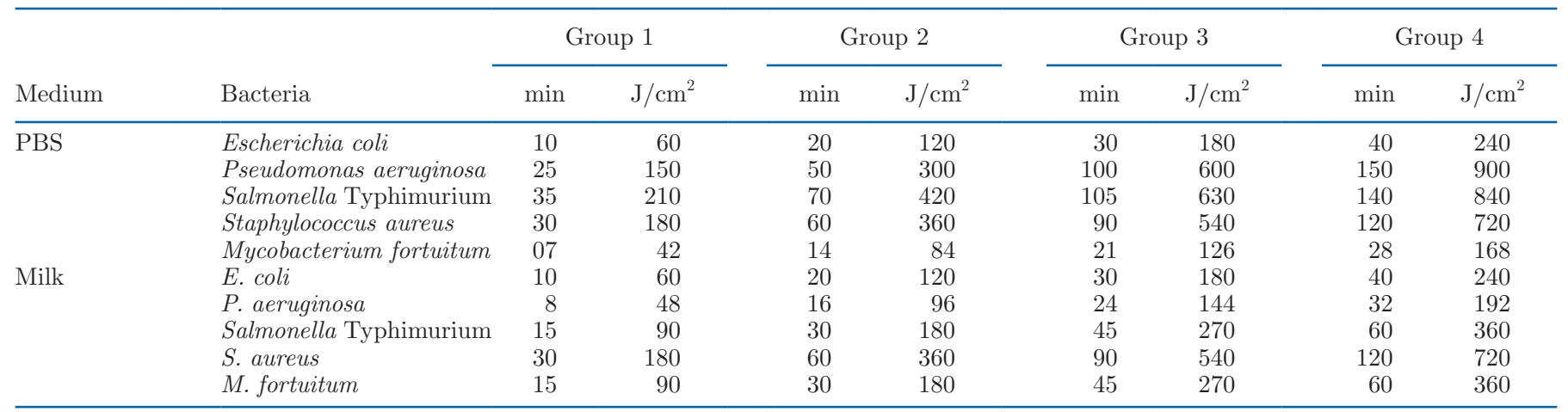

where $N_{0}$ represents initial average number of $\mathrm{cfu} / \mathrm{mL}$ and $N$ is the average number of $\mathrm{cfu} / \mathrm{mL}$ in each respective experimental group, as reported in Table 1.

Inactivation kinetics analysis and lethal dose (LD) values were obtained following methodology described by Chen (2007), who used the Weibull model to fit survival fraction data in function of exposure time.

All microbiological experiments were conducted in triplicates, and replicated in 3 different experimental days, which totalized 9 samples for each experimental group.

\section{Milk Composition Evaluation by Light Spectroscopy (UV-Visible-Infrared)}

We carried out a series of light spectroscopy techniques to analyze possible chemical alterations in the functional groups of the major milk constituents. For this set of experiments, fresh samples of whole UHT milk irradiated by blue light for $2 \mathrm{~h}\left(720 \mathrm{~J} / \mathrm{cm}^{2}\right)$ were compared with nonirradiated control samples. All samples were used in the same day that the recipient was opened and we used UHT processed whole milk to ensure maximum reproducibility in near-infrared (NIR) and Fourier-transform infrared spectroscopy (FTIR) analysis. For the UV-visible and fluorescence analyzes, samples were obtained after the addition of $1 \%$ acetic acid into the milk samples, followed by centrifugation at $7,378 \times g$ for $15 \mathrm{~min}$ at $4^{\circ} \mathrm{C}$. After that, the supernatant was recovered (whey) and used for the subsequent analyzes.

\section{NIR Spectroscopy}

We analyzed the composition of irradiated milk samples to search for any chemical modification of most abundant milk components that could lead to alterations in organoleptic or nutritional properties, or both. Spectra were collected using a Fourier-transform near-infrared spectrometer (MPA, Bruker, Ettlingen, Germany) and the system software Opus 5.5 (Bruker) was used for data acquisition and processing. The NIR measurements were performed within the range 4,000 to $10,000 \mathrm{~cm}^{-1}$. Each spectrum was obtained by 158 scans with a resolution of $8 \mathrm{~cm}^{-1}$. Spectral data were acquired at $25^{\circ} \mathrm{C}$. The percentages of TS, lactose, protein, and fat were quantified using artificial intelligence software (Opus, Bruker).

\section{Attenuated Total Reflectance-FTIR}

The pre- and postirradiated whole milk samples were deposited onto a silicon wafer and dried at $37^{\circ} \mathrm{C}$ for 2 h. The dried samples were then pressed over the sapphire window of an Attenuated Total Reflectance-FTIR (Spectrum, Perkin Elmer, Norwalk, CT) and 40 spectra were recorded from 700 to $3,000 \mathrm{~cm}^{-1}$. Amide I and amide II bands variations were compared by the area under the curves in the 1,485 to $1,715 \mathrm{~cm}^{-1}$ frequency range. Spectra were considered reproducible when spectral peaks did not exceed $5 \%$ of variation in between spectra of the same sample. Background spectra were acquired from a clean Si wafer. Spectra were treated using Opus (Bruker), analyzed using Origin (OriginLab, Northampton, MA), and plotted using Prism (GraphPad, San Diego, CA).

\section{UV-Visible Absorbance and Fluorescence Spectroscopy}

To evaluate the effect of blue light over riboflavin present in the milk whey, the samples were subjected to absorbance and fluorescence spectroscopy. For fluorescence spectra, we used $450 \mathrm{~nm}$ excitation and $470 \mathrm{~nm}$ long-pass filter to measure all luminescence emitted in the 470 to $650 \mathrm{~nm}$ range. 
We added $10 \mu \mathrm{L}$ of glacial acetic acid to $990 \mu \mathrm{L}$ of milk to extract optically clear whey solution by centrifugation at $7,378 \times g$ for $15 \mathrm{~min}$ at room temperature. After that, $300 \mu \mathrm{L}$ of each sample supernatant were placed in a 96-well plate for absorbance and fluorescence analysis using a plate-reader spectrophotometer (Spectramax M4, Molecular Devices, Sunnyvale, CA). The milk samples were compared with samples containing 7.4 $\mu M$ riboflavin (Sigma-Aldrich, Buchs, Switzerland) irradiated for $2 \mathrm{~h}$ and not irradiated. The absolute concentration of riboflavin in whey solution was determined by standard curves obtained from a serial dilution of riboflavin $(0.001-100 \mu M)$ and integrated the area under each respective fluorescence spectrum curve.

\section{Statistical Analysis}

Data of individual survival fractions were defined as the quantity of colony-forming units normalized by taking $\log _{10}$ of said value in treated and untreated control groups. Survival fraction data passed through Shapiro-Wilk test to confirm normality and then were compared with each respective control using one-way ANOVA and Tukey as a post-hoc test. Constituent percentage data obtained from NIR spectroscopy were analyzed by paired Student $t$-test. Statistical tests were performed using GraphPad Prism software, where all inference analyses adopted a significance level of $P<$ 0.05 .

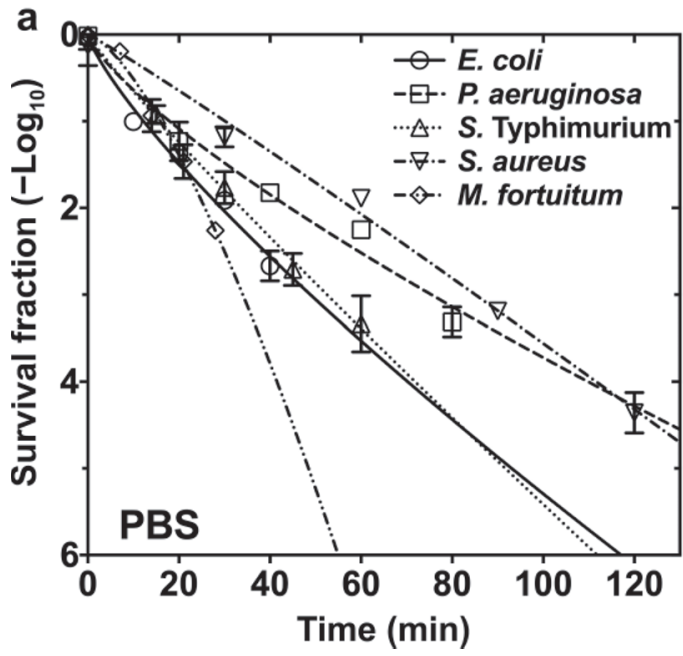

\section{RESULTS}

Figure 1 and Table 2 show that, using our experimental setup, all bacterial samples presented more than $5 \log _{10}(99.999 \%)$ of inactivation in milk within less than $100 \mathrm{~min}\left(600 \mathrm{~J} / \mathrm{cm}^{2}\right)$. Each species presents different inactivation kinetics in PBS (Figure 1a) and milk (Figure 1b). In general terms, irradiation in whole milk improved the antibacterial activity of blue light (i.e., $\mathrm{LD}_{99.999}$ was predominantly lower in milk when compared with PBS). In PBS, $\mathrm{LD}_{99.999}$ varied from 47.8 to 219.03 min depending on bacterial species, with M. fortuitum being the most sensitive and Salmonella Typhimurium the most tolerant. In contrast, E. coli was the most sensitive bacterium $\left(\mathrm{LD}_{99.999}=38.14 \mathrm{~min}\right)$ in milk, whereas $M$. fortuitum was the most tolerant $\left(\mathrm{LD}_{99.999}=97.25 \mathrm{~min}\right)$. Nonirradiated samples did not exhibit any significant level of inactivation or growth during the entire experimental procedure.

Near-infrared spectroscopy analysis did not reveal any variation between irradiated and nonirradiated milk samples (Figure 2a). According to the spectra analysis tool designed specifically to analyze milk composition (Opus, Bruker), no statistically significant differences were observed regarding the percentage of TS, lactose, protein, and fat content (Figure $2 \mathrm{~b}$ ).

The use of FTIR spectroscopy provided an extended molecular analysis (infrared fingerprint range) concerning the most abundant chemical bonds present in milk components. The measured spectra presented in Figure

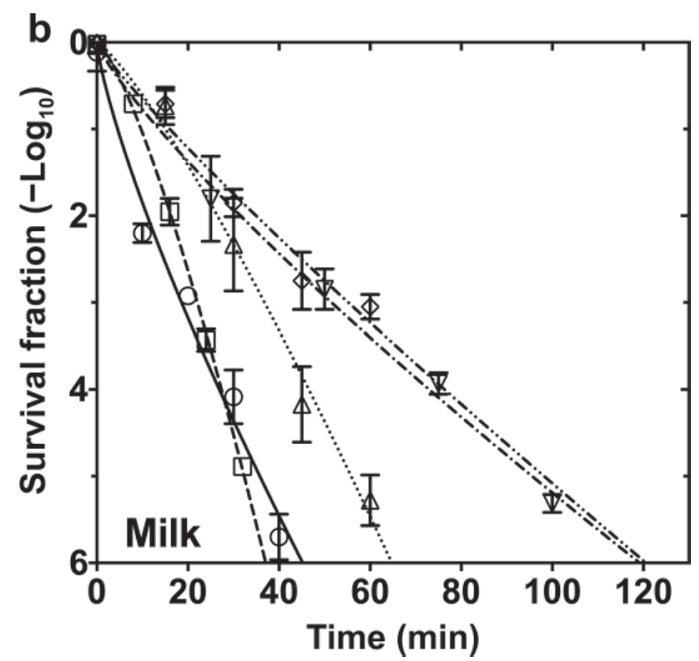

Figure 1. Kinetics of bacterial (Escherichia coli, Pseudomonas aeruginosa, Salmonella Typhimurium, Staphylococcus aureus, and Mycobacterium fortuitum) inactivation induced by blue light $(\lambda=413 \pm 10 \mathrm{~nm})$ irradiation. On the left side (a) are inactivation kinetics data of groups treated in PBS and on the right side (b) are groups treated in milk. Data are presented as survival fraction of $\log _{10}$ reduction in function of irradiation time. The Weibull model was used to fit the inactivation kinetics curves. The error bars indicate SD of the mean at each data point. Error bars are not shown where their height is shorter than symbols. 
Table 2. Lethal dose (LD) values calculated using the Weibull model for bacterial samples inactivated by blue light in PBS and milk ${ }^{1}$

\begin{tabular}{llrrr}
\hline Medium & Bacteria & $\begin{array}{r}\mathrm{LD}_{90} \\
(\mathrm{~min})\end{array}$ & $\begin{array}{r}\mathrm{LD}_{99.9} \\
(\mathrm{~min})\end{array}$ & $\begin{array}{c}\mathrm{LD}_{99.999} \\
(\mathrm{~min})\end{array}$ \\
\hline PBS & Escherichia coli & 13.54 & 52.60 & 100.50 \\
& Pseudomonas aeruginosa & 19.20 & 77.23 & 148.20 \\
& Salmonella Typhimurium & 37.57 & 123.84 & 219.03 \\
& Staphylococcus aureus & 35.58 & 90.04 & 140.17 \\
& Mycobacterium fortuitum & 15.84 & 33.21 & 47.80 \\
Milk & E. coli & 5.38 & 20.39 & 38.14 \\
& P. aeruginosa & 9.88 & 22.19 & 49.83 \\
& Salmonella Typhimurium & 14.26 & 33.84 & 80.32 \\
& S. aureus & 14.47 & 51.06 & 95.83 \\
& M. fortuitum & 15.59 & 54.24 & 97.25 \\
\hline
\end{tabular}

${ }^{1}$ Lethal doses are presented in minutes of irradiation.

3a (lipid region) display no perceptible differences between treated and control whole milk. Figure $3 \mathrm{~b}$ only exhibits a subtle reduction $(3.2 \%)$ in the amide I and amide II absorption bands, possibly indicating minor degradation of nitrogen-containing bonds in irradiated samples. These bonds are most abundant in proteins, but can also be found in other milk components, such as riboflavin. However, such small variation $(<5 \%)$ cannot be considered conclusive.

The only data that indicate relevant degradation of a milk component were obtained from UV-visible absorption (Figure 4a) and fluorescence spectroscopy (Figure $4 \mathrm{~b}$ ). In fact, color alteration of irradiated milk can be appreciated by the naked eye. The treated samples become bleached in relation to controls. To minimize the effects of light scattering in our data, we analyzed the extracted whey solution from milk samples.

The UV-visible absorption spectroscopy indicated the depletion of a compound with absorption peaks at 375 and $450 \mathrm{~nm}$. These absorption peaks have been attributed to riboflavin (vitamin $\mathrm{B}_{2}$ ), which represents a
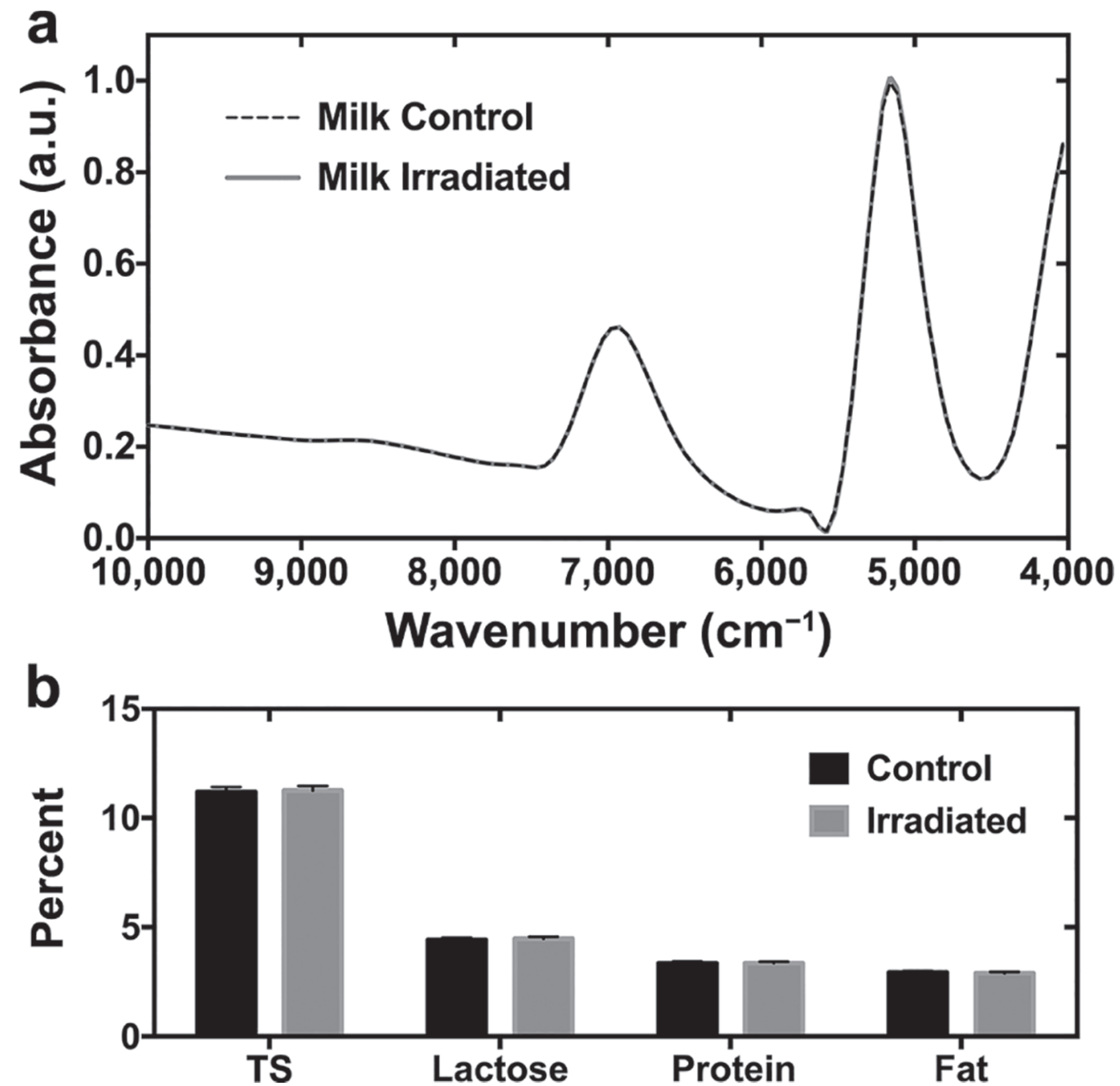

Figure 2. Near-infrared spectra of whole milk samples treated (gray line) and nontreated (black line) by blue light irradiation within the range of 4,000 to $10,000 \mathrm{~cm}^{-1}$ (a). Ratios of TS, lactose, protein, and fat are quantified using artificial intelligence software (Opus, Bruker Optik GmbH, Ettlingen, Germany) based on the obtained spectra. Error bars represent SD of the mean (b). 


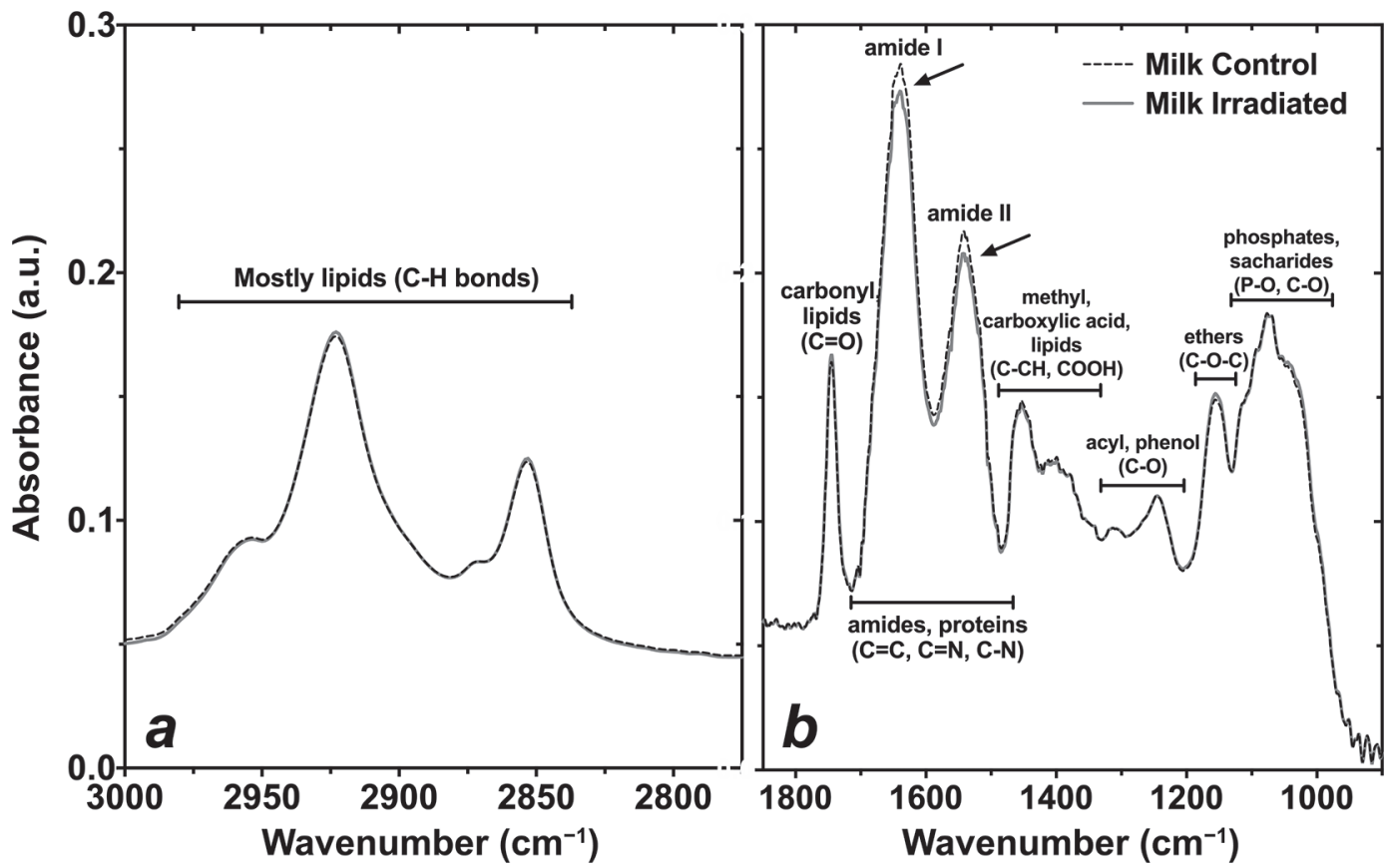

Figure 3. Fourier-transform infrared spectra of control and irradiated whole milk samples in 3,000 to $2,750 \mathrm{~cm}^{-1}$ (a) and 1,850 to $900 \mathrm{~cm}^{-1}$ (b) regions. Note that the only appreciable variations can be observed in the amide I and II bands (indicated by arrows). For all other regions, both spectra merge almost as a single line. a.u. = arbitrary units.

major light-absorbing milk component. Following light absorption spectroscopy, we performed fluorescence spectroscopy to confirm riboflavin degradation and quantify its concentration in samples (Figure 4c). As a matter of fact, fluorescence spectroscopy suggests that riboflavin is the only major milk component absorbing $450 \mathrm{~nm}$ of light and its concentration was depleted by 1,000 times (i.e., from 2.4 to $0.002 \mu M$, Figure 4c) after $2 \mathrm{~h}$ of blue light irradiation $\left(720 \mathrm{~J} / \mathrm{cm}^{2}\right)$.

\section{DISCUSSION}

All bacterial species presented more than $5 \log _{10}$ of inactivation within $2 \mathrm{~h}$ of irradiation by blue light. These highly satisfactory results encourage us to believe that blue light can substitute thermal decontamination processes because dairy industries generally receive milk from producers with contamination levels below $10^{6} \mathrm{cfu} / \mathrm{mL}$. Perhaps, irradiation systems specially designed for industrial milk decontamination could greatly increase the decontamination efficiency using higher light intensities. Hence, exposure time required for blue light inactivation process may become more compatible with an industrial routine.

It is interesting to remark that inactivation efficiency was better in milk than in PBS. The actual reason for this observation is yet unknown; however, we can infer at least 2 influencing factors: (1) riboflavin present in whole milk could act as a photosensitizer and cause further ROS production from photodynamic reactions (Bouillaguet et al., 2010); and (2) milk strongly scatters light and, therefore, it causes a superposition of backscattered light with incident light amplifying the amount of light inside the milk sample (Jacques, 2010).

No qualitative changes could be observed concerning the consistency characteristics of the milk. On the other hand, irradiated milk loses its yellowish shade after the irradiation process, giving potential to also substitute bleaching processes often adopted by dairy industries. It is known that riboflavin is present at levels of a few milligrams per liter in whey concentrates. Riboflavin is also commonly adsorbed onto and incorporated into lactose crystals and is responsible for the yellowish color of edible lactose (Biesalski and Back, 2011). However, riboflavin is very sensitive to UV or visible light (350-520 nm), being decomposed to a nontoxic product after short exposure times (Sattar et al., 1977).

Through our analysis of fluorescence spectroscopy, it was possible to confirm that the color change observed in milk after irradiation was due to the degradation of riboflavin caused by exposure to blue light (Figure 4). When riboflavin is degraded by light, it releases the ribityl chain from the central azole ring, reducing the concentration of carbon-nitrogen bounds in irradiated samples (Biesalski and Back, 2011). Therefore, the slight reduction of amide I and amide II observed in FTIR 

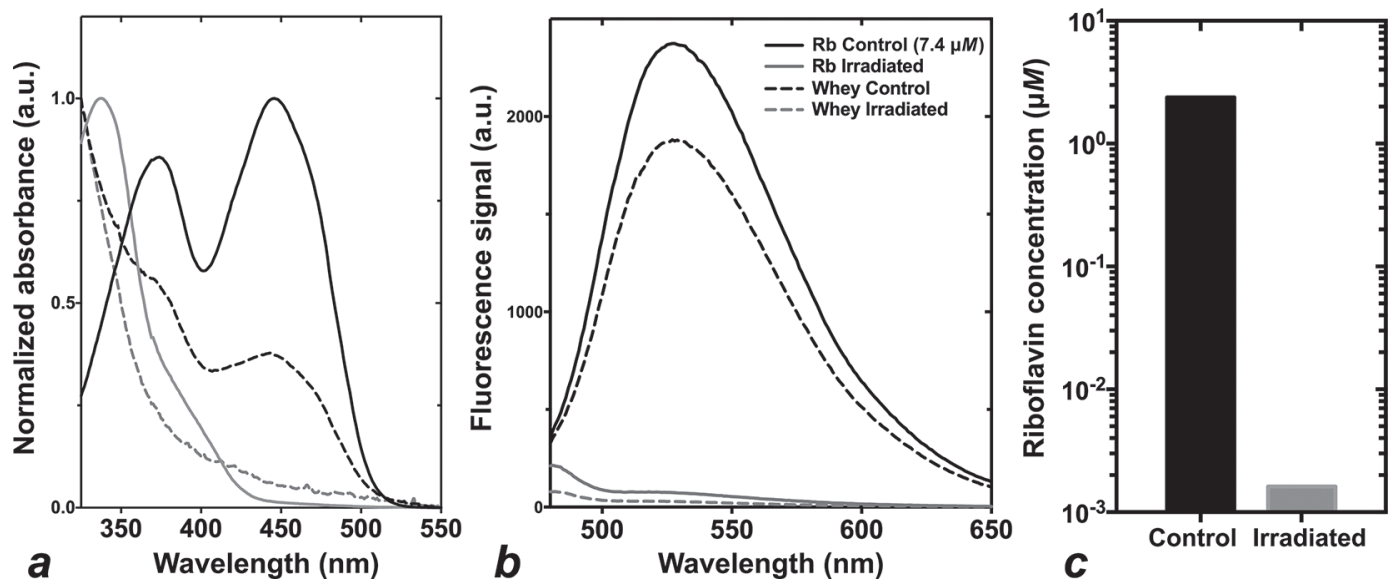

Figure 4. Absorbance (a) and fluorescence (b) spectra obtained from whole milk samples before and after blue light irradiation. According to previously established standard curves of fluorescence intensity, riboflavin (vitamin $\mathrm{B}_{2}$ ) concentration was depleted by 1,000 -fold due to photodegradation (c). a.u. = arbitrary units; $\mathrm{Rb}=$ riboflavin.

analysis could be caused by riboflavin photobleaching and degradation of peptide bonds by photodynamically generated ROS. Nevertheless, riboflavin presents a low commercial cost and can be easily supplemented in dairy products.

The use of blue light in milk processing industries or even in dairy farms could be extremely interesting, as it does not require special training and does not offer occupational hazards. Yet, the photoinactivation approach with visible light is more interesting than UV-C light-based inactivation for the dairy industry because UV-C presents much less penetration in light-scattering aqueous solutions, causes indiscriminate oxidation of biological material, and offers occupational risks for eyes and skin of workers (Kleinpenning et al., 2010). Using blue light is also safer and cheaper than pasteurization and UHT processing because it does not require high-power heating systems such as boilers. In fact, Niels Finsen won the 1903 Nobel Prize for Medicine because he demonstrated that eukaryotic cells are much less sensitive to blue light when compared with bacterial cells (Finsen, 1901). Therefore, blue-lightbased technologies for microbial control have been successfully designed to operate on a continuous basis to decontaminate environments occupied by people, such as industrial plants and hospital wards (Maclean et al., 2010; Maclean et al., 2013).

To ensure the quality of milk throughout the production chain, blue LED systems could be implemented in structures from milking facilities to storage and milk processing (Dai et al., 2013; McDonald et al., 2013). Light-emitting diodes have the advantages of emitting light at specific wavelengths, high photoelectric conversion efficiency (i.e., low thermal output), high durability, and low production cost (Yeh and Chung,
2009). They also produce high light intensities in smallsize units, making it easier for implementation of this technology. In comparison to UHT processing, the light-mediated process also produces smaller carbonfootprints because it is more energy efficient and does not require combustion to operate. Therefore, this technology platform is extremely interesting to industries because it can reduce costs and provide excellent organoleptic, nutritional, and decontamination properties simultaneously.

\section{CONCLUSIONS}

All bacterial species tested presented more than 5 $\log _{10}$ of inactivation within less than $2 \mathrm{~h}$ of irradiation. The infrared spectroscopy analysis did not reveal any significant alteration in any of the milk constituents (e.g., proteins, lipids, and sugars). The only significant alteration to milk constituents was detected by UV-visible spectroscopy that revealed depletion of riboflavin (vitamin $\mathrm{B}_{2}$ ), a minor drawback that can be easily adjusted by supplementation. Therefore, light-mediated decontamination has potential to be taken to industrial scale, reducing costs and improving quality values of dairy products.

\section{ACKNOWLEDGMENTS}

We gratefully thank the Brazilian funding agencies São Paulo Research Foundation (grants 2016/250952; 2013/07937-8; 2016/08593-9; Sao Paulo, Brazil), CAPES (Finance Code 001; Brasilia, Brazil), and the National Council for Scientific and Technological Development (CNPq, grants 141901/2016-0, 465763/2014-6, and 462042/2014-6; Brasilia, Brazil), and the private 
companies BioLambda (Sao Paulo, Brazil) and Bruker do Brasil (Atibaia, Brazil). We thank the User's Chemical Laboratory of the Brazilian Synchrotron Light Laboratory for providing access to the FTIR instrument, Thiago M. dos Santos (Brazilian Synchrotron Light Laboratory, Campinas, Brazil) for technical assistance in the FTIR measurements. N. L. and M. S. R. are research fellows of CNPq (312249/2017-9 and 315738/2018-9).

\section{REFERENCES}

Biesalski, H. K., and E. I. Back. 2011. Riboflavin, nutritional significance. Pages 704-706 in Encyclopedia of Dairy Sciences. Vol. 4. J. W. Fuquay, P. F. Fox, and P. L. H. McSweeney, ed. Academic Press, Amsterdam, the Netherlands.

Boor, K. J., M. Wiedmann, S. Murphy, and S. Alcaine. 2017. A 100Year Review: Microbiology and safety of milk handling. J. Dairy Sci. 100:9933-9951. https://doi.org/10.3168/jds.2017-12969.

Bouillaguet, S., J. C. Wataha, O. Zapata, M. Campo, N. Lange, and J. Schrenzel. 2010. Production of reactive oxygen species from photosensitizers activated with visible light sources available in dental offices. Photomed. Laser Surg. 28:519-525. https://doi.org/ 10.1089 /pho.2009.2505

Chen, H. 2007. Use of linear, Weibull, and log-logistic functions to model pressure inactivation of seven foodborne pathogens in milk. Food Microbiol. 24:197-204. https://doi.org/10.1016/j.fm.2006.06 .004 .

Dai, T., A. Gupta, Y. Y. Huang, R. Yin, C. K. Murray, M. S. Vrahas, M. E. Sherwood, G. P. Tegos, and M. R. Hamblin. 2013. Blue light rescues mice from potentially fatal Pseudomonas aeruginosa burn infection: Efficacy, safety, and mechanism of action. Antimicrob. Agents Chemother. 57:1238-1245. https://doi.org/10.1128/AAC .01652-12.

Diab, M., M. Hamze, R. Bonnet, E. Saras, J.-Y. Madec, and M. Haenni. 2017. OXA-48 and CTX-M-15 extended-spectrum betalactamases in raw milk in Lebanon: Epidemic spread of dominant Klebsiella pneumoniae clones. J. Med. Microbiol. 66:1688-1691. https://doi.org/10.1099/jmm.0.000620.

Finsen, N. 1901. Phototherapy (J. H. Sequeira, Trans. Vol. 1). Edward Arnold, London, UK.

Ghate, V., A. Kumar, W. Zhou, and H.-G. Yuk. 2016. Irradiance and temperature influence the bactericidal effect of 460-nanometer light-emitting diodes on Salmonella in orange juice. J. Food Prot. 79:553-560. https://doi.org/10.4315/0362-028X.JFP-15-394.

Ghate, V., A. L. Leong, A. Kumar, W. S. Bang, W. Zhou, and H. G. Yuk. 2015. Enhancing the antibacterial effect of 461 and $521 \mathrm{~nm}$ light emitting diodes on selected foodborne pathogens in trypticase soy broth by acidic and alkaline $\mathrm{pH}$ conditions. Food Microbiol. 48:49-57. https://doi.org/10.1016/j.fm.2014.10.014.

Ghate, V. S., K. S. Ng, W. Zhou, H. Yang, G. H. Khoo, W. B. Yoon, and H. G. Yuk. 2013. Antibacterial effect of light emitting diodes of visible wavelengths on selected foodborne pathogens at different illumination temperatures. Int. J. Food Microbiol. 166:399-406. https://doi.org/10.1016/j.ijfoodmicro.2013.07.018.

Huang, L., Y. Xuan, Y. Koide, T. Zhiyentayev, M. Tanaka, and M. R. Hamblin. 2012. Type I and Type II mechanisms of antimicrobial photodynamic therapy: An in vitro study on gram-negative and gram-positive bacteria. Lasers Surg. Med. 44:490-499. https://doi .org/10.1002/lsm.22045.

Jacques, S. L. 2010. How tissue optics affect dosimetry of photodynamic therapy. J. Biomed. Opt. 15:051608. https://doi.org/10 $.1117 / 1.3494561$.

Jett, B. D., K. L. Hatter, M. M. Huycke, and M. S. Gilmore. 1997. Simplified agar plate method for quantifying viable bacteria. Biotechniques 23:648-650.
Johler, S., D. Weder, C. Bridy, M.-C. Huguenin, L. Robert, J. Hummerjohann, and R. Stephan. 2015. Outbreak of staphylococcal food poisoning among children and staff at a Swiss boarding school due to soft cheese made from raw milk. J. Dairy Sci. 98:2944-2948. https://doi.org/10.3168/jds.2014-9123.

Kleinpenning, M. M., T. Smits, M. H. A. Frunt, P. E. J. van Erp, P. C. M. van de Kerkhof, and R. M. J. P. Gerritsen. 2010. Clinical and histological effects of blue light on normal skin. Photodermatol. Photoimmunol. Photomed. 26:16-21. https://doi.org/10.1111/ j.1600-0781.2009.00474.x.

Maclean, M., S. J. MacGregor, J. G. Anderson, G. A. Woolsey, J. E. Coia, K. Hamilton, I. Taggart, S. B. Watson, B. Thakker, and G. Gettinby. 2010. Environmental decontamination of a hospital isolation room using high-intensity narrow-spectrum light. J. Hosp. Infect. 76:247-251. https://doi.org/10.1016/j.jhin.2010.07.010.

Maclean, M., L. E. Murdoch, S. J. MacGregor, and J. G. Anderson. 2013. Sporicidal effects of high-intensity $405 \mathrm{~nm}$ visible light on endospore-forming bacteria. Photochem. Photobiol. 89:120-126. https://doi.org/10.1111/j.1751-1097.2012.01202.x.

Matak, K. E., S. S. Sumner, S. E. Duncan, E. Hovingh, R. W. Worobo, C. R. Hackney, and M. D. Pierson. 2007. Effects of ultraviolet irradiation on chemical and sensory properties of goat milk. J. Dairy Sci. 90:3178-3186. https://doi.org/10.3168/jds.2006-642.

McDonald, R. S., S. Gupta, M. Maclean, P. Ramakrishnan, J. Anderson, S. MacGregor, R. Meek, and M. Grant. 2013. 405 nm light exposure of osteoblasts and inactivation of bacterial isolates from arthroplasty patients: Potential for new disinfection applications? Eur. Cell. Mater. 25:204-214. https://doi.org/10.22203/ eCM.v025a15.

Miller, B. M., A. Sauer, and C. I. Moraru. 2012. Inactivation of Escherichia coli in milk and concentrated milk using pulsed-light treatment. J. Dairy Sci. 95:5597-5603. https://doi.org/10.3168/jds .2012-5714.

Palgan, I., I. M. Caminiti, A. Muñoz, F. Noci, P. Whyte, D. J. Morgan, D. A. Cronin, and J. G. Lyng. 2011. Effectiveness of High Intensity Light Pulses (HILP) treatments for the control of Escherichia coli and Listeria innocua in apple juice, orange juice and milk. Food Microbiol. 28:14-20. https://doi.org/10.1016/j.fm.2010.07.023.

Sartori, L., M. R. Fernandes, S. Ienne, T. A. de Souza, L. Gregory, L. Cerdeira, and N. Lincopan. 2017. Draft genome sequences of two fluoroquinolone-resistant CTX-M-15-producing Escherichia coli ST90 (ST23 complex) isolated from a calf and a dairy cow in South America. J. Glob. Antimicrob. Resist. 11:145-147. https:// doi.org/10.1016/j.jgar.2017.10.009

Sattar, A.. J. M. deMan, and J. C. Alexander. 1977. Light-induced degradation of vitamins I. Kinetic studies on riboflavin decomposition in solution. Can. Inst. Food Sci. Technol. J. 10:61-64. https:/ /doi.org/10.1016/S0315-5463(77)73439-X.

Scheldeman, P., L. Herman, S. Foster, and M. Heyndrickx. 2006. Bacillus sporothermodurans and other highly heat-resistant spore formers in milk. J. Appl. Microbiol. 101:542-555. https://doi.org/ 10.1111/j.1365-2672.2006.02964.x.

Sonnier, J. L., J. S. Karns, J. E. Lombard, C. A. Kopral, B. J. Haley, S.-W. Kim, and J. A. S. Van Kessel. 2018. Prevalence of Salmonella enterica, Listeria monocytogenes, and pathogenic Escherichia coli in bulk tank milk and milk filters from US dairy operations in the National Animal Health Monitoring System Dairy 2014 study. J. Dairy Sci. 101:1943-1956. https://doi.org/10.3168/jds.2017-13546.

Srimagal, A., T. Ramesh, and J. K. Sahu. 2016. Effect of light emitting diode treatment on inactivation of Escherichia coli in milk Lebensm. Wiss. Technol. 71:378-385. https://doi.org/10.1016/j .lwt.2016.04.028.

WHO. 2014. Antimicrobial resistance: Global report on surveillance. Vol. 1. WHO Library Cataloguing-in-Publication Data (p. 232). World Health Organization, Geneva, Switzerland.

Yeh, N., and J. P. Chung. 2009. High-brightness LEDs-Energy efficient lighting sources and their potential in indoor plant cultivation. Renew. Sustain. Energy Rev. 13:2175-2180. https://doi.org/10.1016/ j.rser.2009.01.027. 